\title{
Identification of Glyoxalase-I as a Protein Marker in a Mouse Model of Extremes in Trait Anxiety
}

\author{
Simone A. Krömer, Melanie S. Keßler, Dale Milfay, Isabel N. Birg, Mirjam Bunck, Ludwig Czibere, Markus Panhuysen, \\ Benno Pütz, Jan M. Deussing, Florian Holsboer, Rainer Landgraf, and Christoph W. Turck \\ Max-Planck Institute of Psychiatry, D-80804 Munich, Germany
}

\begin{abstract}
For $>15$ generations, CD1 mice have been selectively and bidirectionally bred for either high-anxiety-related behavior (HAB-M) or low-anxiety-related behavior (LAB-M) on the elevated plus-maze. Independent of gender, HAB-M were more anxious than LAB-M animals in a variety of additional tests, including those reflecting risk assessment behaviors and ultrasound vocalization, with unselected CD1 "normal" control (NAB-M) and cross-mated (CM-M) mice displaying intermediate behavioral scores in most cases. Furthermore, in both the forced-swim and tail-suspension tests, LAB-M animals showed lower scores of immobility than did HAB-M and NAB-M animals, indicative of a reduced depression-like behavior. Using proteomic and microarray analyses, glyoxalase-I was identified as a protein marker, which is consistently expressed to a higher extent in LAB-M than in HAB-M mice in several brain areas. The same phenotypedependent difference was found in red blood cells with NAB-M and CM-M animals showing intermediate expression profiles of glyoxalase-I. Additional studies will examine whether glyoxalase-I has an impact beyond that of a biomarker to predict the genetic predisposition to anxiety- and depression-like behavior.
\end{abstract}

Key words: anxiety; enzyme; biomarker; proteomics; $\mathrm{HAB}$; depression; animal model; microarray

\section{Introduction}

By definition, a proper animal model to study behavioral, neuroendocrine, and genetic concomitants of trait anxiety, including psychopathology, should represent a good approximation to score symptoms of anxiety disorders and possibly comorbid depression (Finn et al., 2003; Cryan and Mombereau, 2004; Gordon and Hen, 2004). To avoid interstrain comparisons, likely to reveal differences in more than just anxiety-related indices, intrastrain breeding approaches were used to focus on particular traits, including anxiety-related behavior (Landgraf and Wigger, 2003), depression-like behavior (El Yacoubi et al., 2003), avoidance behavior, or receptor functions likely to be associated with differences in anxiety (Ohta et al., 1999; Brush, 2003; Overstreet et al., 2003; Steimer and Driscoll, 2003). The technique of selective bidirectional breeding enhances the representation (frequency) of genetic material associated with a particular trait shifting the animals' phenotype bidirectionally from the strain mean (Falconer and Mackay, 1996).

Wistar rats bred for either high-anxiety-related behavior $(\mathrm{HAB})$ or low-anxiety-related behavior (LAB) represent extremes in trait anxiety and comorbid depression-like behavior (Landgraf and Wigger, 2002, 2003; Landgraf and Neumann, 2004; Murgatroyd et al., 2004; Wigger et al., 2004), with HAB

Received Aug. 6, 2004; revised March 8, 2005; accepted March 9, 2005.

We thank M. Zimbelmann and M. Nussbaumer for behavioral testing and W. Jacob, E. Frank, J. Artmann, J. Auracher, C. Reinel, C. Tatarau, and M. Wolf for their contribution to USV measurements.

Correspondence should be addressed to Dr. Christoph W. Turck, Max-Planck Institute of Psychiatry, Kraepelinstrasse 2, D-80804 Munich, Germany. E-mail: turck@mpipsykl.mpg.de.

D0I:10.1523/JNEUROSCI.0115-05.2005

Copyright $\odot 2005$ Society for Neuroscience $\quad$ 0270-6474/05/254375-10\$15.00/0 animals as hyperanxious on the key selection criterion, elevated plus-maze (EPM), and a variety of additional paradigms, including dark-light box, modified hole board, social interaction, and home cage watching (Henniger et al., 2000; Ohl et al., 2001). Moreover, the HAB animals prefer to use passive coping strategies after stressor exposure and negative associations in assessing the emotional impact of a given scenario. The hypothesis of an inborn bias and high-stress vulnerability is further supported by investigations on $\mathrm{HAB}$ pups, which, after separation from their mothers, vocalize more than LAB pups as early as postnatal day 11 (P11) (Wigger et al., 2001). Furthermore, the hypothalamuspituitary-adrenal axis of adult $\mathrm{HAB}$ rats is hyper-reactive, including a pathological outcome of the dexamethasone/corticotropinreleasing hormone challenge test, thus mimicking a clinically relevant feature typical of psychiatric patients (Keck et al., 2002). Although $\mathrm{HAB} / \mathrm{LAB}$ rats represent a powerful tool for the study of behavioral and neuroendocrine parameters of trait anxiety and comorbid depression, and to explore environmental modulation of genetic predisposition (Finn et al., 2003), the possibilities for additional genetic approaches are a priori limited in the rat. Genetic approaches currently available in the mouse make this model organism particularly powerful for the functional analysis of candidate genes and in defining gene products underlying trait anxiety and possibly depression (Tarantino and Bucan, 2000). Therefore, we describe the generation and validation of hyperanxious (HAB-M) and hypoanxious (LAB-M) CD1 mouse lines as model of extremes in trait anxiety.

The manifestation of anxiety in a number of psychiatric disorders such as generalized anxiety disorder, depression, panic attacks, phobias, obsessive-compulsive disorders, and posttraumatic stress disorders (Gross and Hen, 2004) highlights the im- 
portance of gaining a better understanding of associated reliable biomarkers in proper animal models. Therefore, we used proteomics to look for anxiety-related protein markers serving as one approach to differentiate multiple genetic predispositions to anxiety. Here, we show for the first time that glyoxalase-I (Glx1), which attracts increasing attention for its role in psychopathogenic mechanisms (Chen et al., 2004), is a biomarker in the newly developed mouse model of extremes in trait anxiety, allowing to predict the genetic predisposition to anxiety.

\section{Materials and Methods}

\section{Subjects}

The animal studies were conducted in accordance with the Guide for the Care and Use of Laboratory Animals of the Government of Bavaria. Mice were housed in groups of three to five in plastic cages $(25 \times 20 \times 14 \mathrm{~cm})$ with a $12 \mathrm{~h}$ light/dark schedule (lights on at 6:00 A.M.) at $23^{\circ} \mathrm{C}, 60 \%$ humidity, with food and tap water available ad libitum. Experiments were performed between 8:00 A.M. and 12:00 P.M. We used >250 animals from $>25$ litters of the outbred Swiss CD1 strain (Charles River, Sulzfeld, Germany) as a starting point for selective and bidirectional breeding for anxiety-related behavior on the EPM at 7 weeks of age. Males and females that spent either the least or most time on the open arms of the EPM were mated to establish the HAB-M and LAB-M mouse lines, respectively. The first generation (G1) was weaned and separated by gender at 3 weeks of age and tested on the EPM 4 weeks later. Again, extremes were mated, and offspring were reared in the same manner for all following generations. Outbreeding across families but within closed lines was practiced to minimize random fixation of alleles other than those selected for, and to maximize the number of genes, influencing anxiety-related behavior within each line. After nine generations of outbreeding, an inbreeding protocol was started based on strict sibling mating. We generated four to six independent families within the HAB-M and LAB-M lines, respectively. In the experiments, animals from all inbred HAB-M and LAB-M families from seven generations (G12-G18) were included to avoid both fortuitous correlations and fluctuations across time caused by genetic drift, as described by El Yacoubi et al. (2003) for locomotor activity.

Four to five generations were produced each year. Cross-mated offspring (CM-M) comprised reciprocal crosses between HAB-M and LAB-M mice (i.e., HAB-M $\times$ LAB-M and LAB-M $\times$ HAB-M). They were housed under the same conditions as HAB-M, LAB-M, and "normal" CD1 (NAB-M) animals, the latter selected as controls independent of their performance on the EPM.

All tests were conducted during 7-13 weeks of age. All mice were initially tested on the EPM and, at least $2 \mathrm{~d}$ later, in one or more additional tests. In the latter case, the test order was EPM, followed by the dark-light avoidance or open-arm exposure tests, the tail-suspension test, and finally the forced swimming test. The minimum recovery time between tests was $1 \mathrm{~d}$. If, for instance, mice were only tested in the forced swim test $2 \mathrm{~d}$ after the initial EPM test, the results were quite similar, indicating that behavioral differences among HAB-M, LAB-M, NAB-M, and $\mathrm{CM}-\mathrm{M}$ mice are not attributable to the order of testing (data not shown).

\section{Experiment 1: EPM test and locomotion}

The EPM was made of black plastic and consisted of two open arms $(30 \times$ $5 \mathrm{~cm} ; 100$ lux $)$ and two enclosed arms $(30 \times 5 \times 15 \mathrm{~cm} ; 10$ lux $)$. The arms extended from a central platform $(5 \times 5 \mathrm{~cm}$; $90 \mathrm{lux})$. The EPM was located $120 \mathrm{~cm}$ above the floor. Male and female mice were carried into the EPM room $24 \mathrm{~h}$ before testing and stayed in their home cages until the experiment was performed. At the beginning of the experiment, each mouse was placed on the central platform facing a closed arm. During the 5 min test, the percentage of time spent on the open arms, the number of entries into the closed and open arms, and the latency to the first openarm entry were scored using the "plus-maze" software (E. Fricke, Munich, Germany). Mice were considered to have entered an open or closed arm when both front paws and front shoulders were on the arm, but full entries (all four paws) also were counted. After each test, the EPM was cleaned with water containing detergent or with ethanol (when male and female mice were tested on the same apparatus) and dried with tissue.

In addition to test-related locomotor activity, home cage locomotion of group-housed male and female HAB-M, NAB-M, and LAB-M mice was scored every $10 \mathrm{~min}$ from 8:00 A.M. to 12:00 P.M. (i.e., during the regular testing time) ( $n=4$ cages in each case).

\section{Experiment 2: dark-light avoidance test}

The dark-light box was open topped and consisted of one black-colored, darkened $(15 \times 20 \times 26 \mathrm{~cm} ; 13$ lux $)$ and one white-colored, illuminated $(29 \times 20 \times 26 \mathrm{~cm} ; 650-700$ lux $)$ box, connected through an aperture $(5.0 \times 7.0 \mathrm{~cm})$. In each compartment, the base was lined into $6.5 \times 6.5$ $\mathrm{cm}$ squares. At the beginning of the experiment, each mouse was placed in the center of the lightened box facing the port. During the 5 min test, the percentage of time a mouse spent in the lit compartment was scored using Eventlog 1.0 (EMCO Software, Reykjavik, Iceland). A mouse was defined to have entered the lit or dark box when both front paws and front shoulders were inside the respective compartment. In addition, line crossings, transitions, and the number of exploratory rearings in both the dark and lit compartments were scored. For the cleaning procedure, see Experiment 1.

\section{Experiment 3: open-arm exposure test}

One open arm of the EPM was separated from the central field by a plastic board, making it impossible for the mouse to leave the open arm. At the beginning of the experiment, each mouse was placed onto the open arm facing the board. During the 5 min test, the time a mouse spent with head dipping was recorded. For the cleaning procedure, see Experiment 1.

\section{Experiment 4: ultrasound vocalization test}

Following the developmental pathways that lead to the selectively bred phenotypes, pups from $\geq 18$ litters were separated from both the litter and their HAB-M, NAB-M, or LAB-M mothers at P5. Each pup was weighed and then gently placed on a Petri dish (diameter, $10 \mathrm{~cm}$; kept at $23^{\circ} \mathrm{C}$ ) without the possibility of smelling or hearing its litter. Pups were not separated by gender and tested in a random order. Using a Mini-3 Bat-Detector (Ultrasound Advice, London, UK), ultrasound vocalization was recorded for 5 min using a WM-D6C tape recorder (Sony Professional, Cologne, Germany). For analysis, the number of short shouts $(\sim 60-80 \mathrm{kHz})$ released by each pup was counted.

In additional groups of pups (from at least seven litters), either vehicle $(2.5 \mathrm{ml} / \mathrm{kg}$ body weight; saline containing $0.05 \%$ Tween 80 ) or diazepam ( $2 \mathrm{mg} / \mathrm{kg}$ body weight; $2 \mathrm{ml}$ vial diluted with saline; Ratiopharm, Ulm, Germany) was administered intraperitoneally on P3, P4, and P5. Thirty min and $24 \mathrm{~h}$ after the last injection, both ultrasound vocalization (USV) test calls and grid crossings were counted. To measure the grid crossings, each pup was placed on a Petri dish (diameter, $10 \mathrm{~cm}$ ), which was lined into $2 \times 2 \mathrm{~cm}$ squares. The number of line crossings (two forepaws across the line) each animal made were counted during a 5 min period.

\section{Experiment 5: tail-suspension test}

Animals were suspended by the end of their tail to a bar that was $35 \mathrm{~cm}$ above the floor with adhesive scotch tape. At the end of each videotaped 6 min trial, the duration of total immobility was scored using Eventlog 1.0 (EMCO Software). Four animals were tested during each test.

\section{Experiment 6: forced swim test}

Each mouse was placed in a glass cylinder (height, $23.5 \mathrm{~cm}$; diameter, 11 $\mathrm{cm}$ ) containing $15 \mathrm{~cm}$ of water at $22-23^{\circ} \mathrm{C}$ for $6 \mathrm{~min}$. At the end of each videotaped trial, immobility time (floating) was scored using Eventlog 1.0 (EMCO Software). A mouse was judged immobile when it stopped any movements except those that were necessary to keep its head above water.

\section{Experiment 7: proteomic analyses}

Protein sample preparation. Three to $5 \mathrm{~d}$ after behavioral testing (EPM only or additional tail-suspension or dark-light tests), HAB-M, NAB-M, $\mathrm{CM}-\mathrm{M}$, and LAB-M mice were killed under isoflurane anesthesia, their trunk blood was collected (see below, Western blot analysis), and their brains were removed. The hypothalamus [containing the paraventricular nucleus (PVN) and supraoptic nucleus), amygdala (containing the baso- 
lateral, central, and medial nuclei), and motor cortex were dissected according to the mouse brain atlas (Paxinos and Franklin, 2001). Whereas in rats, the former areas are well known to be critically involved in the HAB versus LAB phenotypes, the motor cortex does not show apparent line differences (Kalisch et al., 2004; Salomé et al., 2004) and has been dissected for comparison. The areas were weighed and immediately frozen in liquid nitrogen. Brain specimens were prepared for two-dimensional (2D) PAGE with the PlusOne Sample Preparation kit (Amersham Biosciences, Piscataway, NJ) using isoelectric focusing (IEF) rehydration buffer ( $7 \mathrm{M}$ urea, $2 \mathrm{~m}$ thiourea, $0.2 \%$ biolytes 3-10, 2\% 3-[(3-cholamidopropyl)dimethylammonio]-1-propanesulfonate, $100 \mathrm{~mm}$ DTT supplemented with the protease inhibitor mixture "Complete," PMSF, and pepstatin). The number of animals analyzed is provided in the figures.

2D PAGE. The brain area extract with $300 \mu \mathrm{g}$ of protein in IEF sample buffer was applied to a $17 \mathrm{~cm}, \mathrm{pH} 4-7$, immobiline strip (Bio-Rad, Hercules, CA) by active rehydration using paper wicks. First-dimension electrophoresis was then performed until 60,000 $V_{\mathrm{h}}$ was reached. For reduction and alkylation of the proteins, the strips were equilibrated in $2 \%$ DTT for $30 \mathrm{~min}$ and then in $2.5 \%$ iodoacetamide for $30 \mathrm{~min}$. For seconddimension SDS-PAGE, strips were layered on top of a $5 \%$ stacking gel and $12 \%$ separating gel and run at $50-200 \mathrm{~V}$ overnight. Gels were stained with colloidal Coomassie blue and scanned. The scanned images were analyzed and compared with each other with the help of PDQuest software (Bio-Rad).

Mass spectrometry. Gel spots that represented differences in protein expression levels based on the results from the image analysis were subjected to an in-gel tryptic digest. For this purpose, $50 \mu \mathrm{l}$ of $20 \mathrm{~mm}$ ammonium bicarbonate/acetonitrile (1:1) was used for gel cleanup and drying. After the gel pieces were dry, $30 \mu \mathrm{l}$ of $20 \mathrm{~mm}$ ammonium bicarbonate containing $0.5 \mu \mathrm{g}$ of trypsin (Promega, Madison, WI) was added and incubated at $37^{\circ} \mathrm{C}$ overnight. Peptides were extracted twice with $25 \mu \mathrm{l}$ of $5 \%$ formic acid by incubation at $37^{\circ} \mathrm{C}$ for $30 \mathrm{~min}$. The extracts were concentrated in a speedvac and redissolved in $12 \mu \mathrm{l}$ of $0.1 \%$ formic acid. For mass spectrometry (MS) analysis, the tryptic digests were injected onto a C18 cartridge using a FAMOS Autosampler (Dionex, Sunnyvale, CA). After washing the cartridge with $0.1 \%$ formic acid (solvent A) for 15 min, the peptides were eluted onto a Picofrit column (New Objective, Woburn, MA) by applying a linear gradient of acetonitrile:water:formic acid (90:10:0.1) for 60 min. The Picofrit eluate was directly infused into an LCQ DECA XP PLUS iontrap mass spectrometer (Thermo Electron, San Jose, CA). Each full scan was followed by a zoom scan and an MS/MS scan of the most intense signal. The resulting MS/MS data were used to search a nonredundant protein database (National Center for Biotechnology Information, Bethesda, MD) using TURBOSEQUEST (J. Yates III and J. Eng, University of Washington, Seattle, WA).

Western blot analysis. The Western blot analysis enabled us to screen a number of blood samples from HAB-M, NAB-M, CM-M, and LAB-M animals. As mentioned previously, all animals were killed 3-5 d after their last behavioral testing. To further test the validity of Glx1 as a biomarker of trait anxiety in mice, blood samples were taken from male C57BL/ 6 and BALB/c animals ( $n=7$ each) $3 \mathrm{~d}$ after the EPM test. Furthermore, to examine the predictive validity of Glx 1 expression in red blood cells, the HAB-M versus LAB-M phenotype was determined in 17 blood samples in a blind manner.

Red blood cells were isolated from $0.8 \mathrm{ml}$ of mouse blood that had been collected in EDTA tubes supplemented with Trasylol. The red cell pellet was frozen at $-80^{\circ} \mathrm{C}$ until use. For red cell lysis, the pellets were thawed on ice, cold water containing $1 \mathrm{~mm}$ PMSF was added, and the suspension was mixed. After the removal of cellular debris, the supernatant was stored in aliquots at $-80^{\circ} \mathrm{C}$. For Western blot, $100 \mu \mathrm{g}$ of total protein from each red cell lysate was run in each gel lane. Electrophoresis was performed on a $15 \%$ miniature gel (Bio-Rad), and the proteins were transferred to an Immobilon polyvinylidene difluoride (PVDF) membrane (Millipore, Bedford, MA) at $100 \mathrm{~V}$ for $1 \mathrm{~h}$ with cooling. The membrane was treated with $5 \%$ Carnation instant nonfat dry milk (Nestlé, Vevey, Switzerland) in TBS plus Triton X-100 (TBST) overnight and rinsed in TBST. The membrane was then incubated with Glx1 antiserum (kindly provided by Dr. Kenneth Tew, Fox Chase Cancer Center, Philadelphia, PA) at a 1:2000 dilution in TBST for $2 \mathrm{~h}$ at room temperature
(RT) and washed with water and TBST for 15 min. Incubation with protein A horseradish peroxidase (Amersham Biosciences) was performed for $40 \mathrm{~min}$ at RT, after which the membrane was washed with water and TBST. Finally, the membrane was incubated with ECL mixture (Amersham Biosciences) for $1 \mathrm{~min}$ and exposed to ECL film (Amersham Biosciences). The membrane was scanned and the signal strength of the Glx1 bands (optical density) assessed with QuantityOne software (Bio-Rad).

\section{Experiment 8: microarray}

Male HAB-M and LAB-M animals ( $n=6$ each) were killed by cervical dislocation $3 \mathrm{~d}$ after the initial EPM test and then brains were shockfrozen in methylbutan and stored at $-80^{\circ}$ until cutting with a Microm (Walldorf, Germany) MH 560 M Cryostat in $200 \mu \mathrm{m}$ slices. The region containing the hypothalamic PVN (two slices) was obtained from these slices by micropunching on dry ice using a sample corer of $1 \mathrm{~mm}$ diameter (Fine Science Tools, Heidelberg, Germany); the PVNs of two nonrelated animals were pooled into one sample, giving a total of three samples for each line. Total RNA was isolated from these punches using the TRIzol (Invitrogen, Karlsruhe, Germany) and chloroform method and amplified with an Ambion (Austin, TX) Amino Allyl MessageAmp amplified RNA (aRNA) kit in two rounds, according to the protocol of the manufacturer. RNA integrity was tested by electrophoresis. Equal amounts of total aRNA were pooled to one common HAB-M and one LAB-M sample containing $40 \mu \mathrm{g}$ of aRNA each and dye coupled using indirect labeling. To exclude dye bias, one-half of each sample was coupled to cyanine 3 (Cy3) and the other one-half to Cy5. The pooled samples were hybridized on five Max-Planck Institute $24 \mathrm{k}$ mouse cDNA arrays (Max-Planck Institute of Psychiatry, Munich, Germany) for each dye coupling combination and scanned on a PerkinElmer Life Sciences (Rodgau-Jügesheim, Germany) ScanArray 4000 laser scanner.

\section{Data analysis}

The data presented as means \pm SEM were analyzed using the Statistica 6.1 software (StatSoft, Tulsa, OK). Both behavioral data and average optical density units were first assessed by a one-way completely randomized ANOVA using line as factor. Except for the behavioral data from the USV test, in which pups could not be separated according to their gender, a two-way ANOVA (line by gender) followed. When appropriate, specific comparisons were made using a post hoc NewmanKeuls test and Bonferroni correction to adjust for multiple comparisons.

The microarray data analysis was accomplished by the fixed circle quantification method using QuantArray (PerkinElmer Life Sciences) and a nonlinear regression method (Yang et al., 2002) with program $\mathrm{R}$

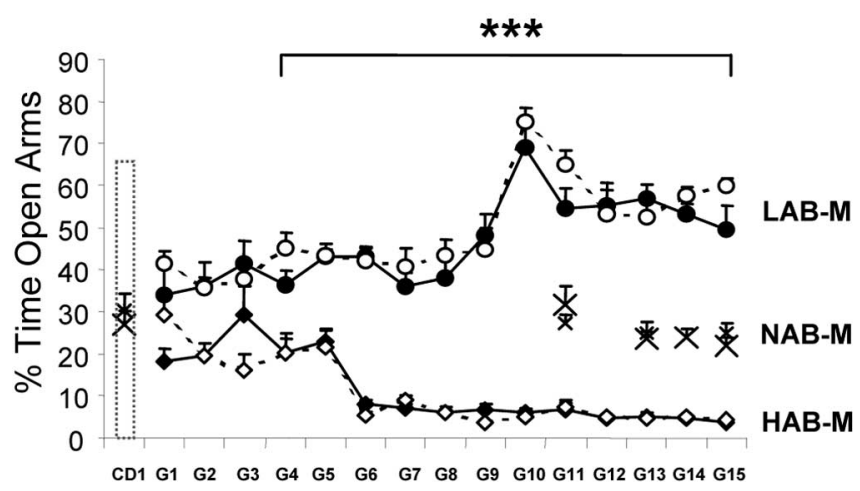

Figure 1. EPM data (percentage of time open arms) of the parental male and female CD1 mice (8+ SEM and range) and G1-G15 generations of male and female HAB-M and LAB-M mice. CD1 mice selected as controls independent of their performance (NAB-M) are shown for comparison (G11, G13-G15). Male animals are indicated by solid lines and filled rhombs and circles, and females are indicated by dotted lines and empty rhombs and circles. Male and female NAB-M animals are displayed as bigger and smaller crosses, respectively. Independent of gender, HAB-M and LAB-M animals differed significantly in their anxiety-related behavior (G4-G15), and NAB-M differed significantly from both HAB-M and LAB-M animals ( $n=$ $40-80$ per line and generation; $\left.{ }^{* * *} p<0.001\right)$. 
A

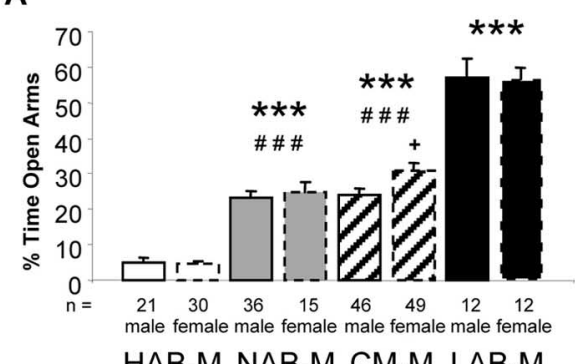

HAB-M NAB-M CM-M LAB-M
B

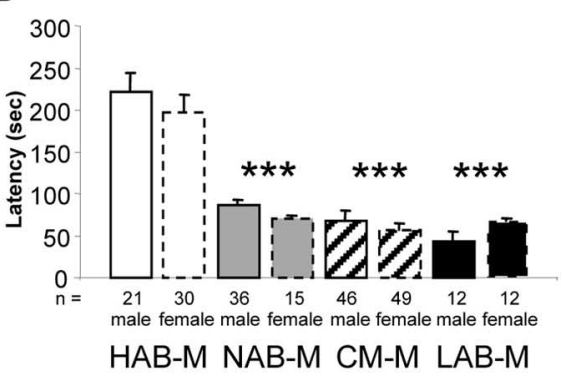

Figure 2. EPM behavior of male and female HAB-M, NAB-M, CM-M, and LAB-M animals. $A, B$, Percentage of time spent on the open arms $(\boldsymbol{A})$ and latency to the first entry into an open arm $(\boldsymbol{B}) .{ }^{* * *} p<0.001$ versus HAB-M; ${ }^{* \# \#} p<0.001$ versus LAB-M; ${ }^{+} p<0.05$ versus NAB-M. Results represent data from G13-G14.

(http://www.r-project.org). A $p$ value $<0.05$ was considered statistically significant.

\section{Results}

\section{Experiment 1: EPM test and locomotion}

The time that outbred CD1 mice spent on the open arms of the EPM ranged from 0 to $54.6 \%$ for males and from 0 to $65.1 \%$ for females. The increasing divergence between HAB-M and LAB-M animals is depicted in Figure 1, with the former showing significantly heightened anxiety-related behavior compared with that of their LAB-M counterparts (G4-G15, $p<0.001)$. Independent of gender, both selected lines differed significantly from unselected NAB-M controls, as shown in Figure 1 for G11 and G13-G15.

Accordingly, male and female HAB-M mice spent a lower percentage and LAB-M mice a higher percentage of time on the open arms than did NAB-M and CM-M animals (males, $F_{(3,111)}=54.2$; females, $\left.F_{(3,102)}=54.1 ; p<0.001\right)$ (Fig. $2 A$ ). There was no difference in the latency until the first open-arm entry among the LAB-M, NAB-M, and CM-M mice for either gender. In contrast, latency until the first open-arm entry was significantly higher in the HAB-M animals compared with that in all other lines (males, $F_{(3,111)}=27.2$; females, $\left.F_{(3,102)}=30.2 ; p<0.001\right)$ (Fig. 2 B).

Indices of EPM-related locomotor activity (Table 1) may be more (open and ratio open/total arm entries) or less (closed-arm entries) contaminated with anxiety (File, 2001) and can thus be misleading (Henderson et al., 2004). Indeed, closed-arm entries and open-arm entries (two-paw and four-paw entries correlated with $r=0.85 ; p<0.001 ; n=221$ ) (Table 1) and the ratio of open/total entries give rise to quite different interpretations with regard to the role of locomotion in anxiety-related behavior. Even closed-arm entries thought to represent an appropriate index of locomotor activity (File, 2001) are of limited value, because LAB-M mice, which spent $>50 \%$ of their time on the open arms, necessarily showed fewer entries into the closed arms than HAB-M animals. Therefore, we also measured home-cage activity, which indicated the tendency of suppressed locomotion in male and female HAB-M animals relative to NAB-M animals and increased locomotion in LAB-M rats (Table 1).

\section{Experiment 2: dark-light avoidance test}

Independent of gender, LAB-M mice spent a significantly higher percentage of time in the light compartment compared with HAB-M and NAB-M animals (males, $F_{(2,60)}=10.6 ; p<0.001$; females, $F_{(2,67)}=6.54 ; p<0.01$ ) (Fig. $3 A$ ). No difference was found between $\mathrm{HAB}-\mathrm{M}$ and NAB-M mice. The number of rearings in both the dark and the light compartments was lower for HAB-M than for NAB-M and LAB-M animals (males, $F_{(2,60)}=$ 64.0; females, $F_{(2,67)}=133 ; p<0.001$ ) (Fig. 3B), and the number for NAB-M was lower than that for LAB-M mice $(p<0.001)$. The number of line crossings for HAB-M animals was lower than that for LAB-M and NAB-M animals (males, $F_{(2,60)}=41.0$; females, $\left.F_{(2,67)}=116 ; p<0.001\right)$, and the latter made fewer line

Table 1. Indices of locomotor activity of male and female HAB-M, NAB-M, CM-M, and LAB-M mice in the EPM, the dark-light avoidance test, and the home cage

\begin{tabular}{|c|c|c|c|c|}
\hline & HAB-M & NAB-M & CM-M & LAB-M \\
\hline \multicolumn{5}{|l|}{ Males } \\
\hline Elevated plus-maze test & $n=21$ & $n=36$ & $n=46$ & $n=12$ \\
\hline Closed-arm entries (two paws) & $11.1 \pm 0.9$ & $12.8 \pm 0.6^{\# \# \#}$ & $15.4 \pm 0.6^{* *, \# \# \#}$ & $6.9 \pm 1.0^{* * *}$ \\
\hline Open-arm entries (two paws) & $1.0 \pm 0.4$ & $5.7 \pm 0.4^{* * * \# \# \#}$ & 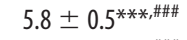 & $8.9 \pm 0.9^{* * *}$ \\
\hline Open-arm entries (four paws) & $0.2 \pm 0.2$ & 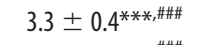 & 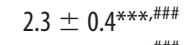 & $8.6 \pm 1.0^{* * *}$ \\
\hline Ratio open/total entries (\%) & $6.0 \pm 1.9$ & $30.6 \pm 1.9^{* * *, \# \# \#}$ & 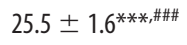 & $56.6 \pm 4.8^{* * *}$ \\
\hline Dark-light avoidance test & $n=23$ & $n=12$ & & $n=28$ \\
\hline Transitions & $11.3 \pm 1.8$ & $19.8 \pm 2.5^{* *, \# \# \#}$ & & $10.0 \pm 1.1$ \\
\hline Line crossings total & $92.9 \pm 7.7$ & $153 \pm 13.5^{*, \# \# \#}$ & & $265 \pm 17.4^{* * *}$ \\
\hline Home cage activity (8:00 A.M. to 12:00 A.M.) & $n=4$ & $n=4$ & & $n=5$ \\
\hline Locomotion (\%) & $0.7 \pm 0.5$ & $1.6 \pm 0.6^{\#}$ & & $8.5 \pm 1.5^{*}$ \\
\hline \multicolumn{5}{|l|}{ Females } \\
\hline Elevated plus-maze test & $n=30$ & $n=15$ & $n=49$ & $n=12$ \\
\hline Closed-arm entries (two paws) & $12.3 \pm 1.2$ & $15.1 \pm 1.4^{\# \# \#}$ & $13.3 \pm 0.4^{\# \# \#}$ & $7.0 \pm 1.0^{* * *}$ \\
\hline Open-arm entries (two paws) & $1.2 \pm 0.3$ & $6.1 \pm 0.7^{* * *, \#}$ & $6.3 \pm 0.5^{* * *, \#}$ & $8.4 \pm 0.6^{* * *}$ \\
\hline Open-arm entries (four paws) & $0.2 \pm 0.1$ & 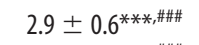 & 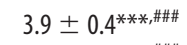 & $7.9 \pm 0.7^{* * *}$ \\
\hline Ratio open/total entries (\%) & $7.6 \pm 1.5$ & 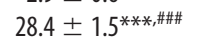 & $30.4 \pm 1.7^{* * *, \# \#}$ & $55.8 \pm 3.9^{* * *}$ \\
\hline Dark-light avoidance test & $n=28$ & $n=12$ & & $n=30$ \\
\hline Transitions & $7.6 \pm 1.2$ & $23.9 \pm 3.2^{* * * \# \# \#}$ & & $14.6 \pm 1.5^{* *}$ \\
\hline Line crossings total & $74.6 \pm 7.2$ & $172 \pm 10.5^{* * *, \# \# \#}$ & & $288 \pm 12.6^{* *}$ \\
\hline Home cage activity (8:00 A.M. to 12:00 P.M.) & $n=4$ & $n=4$ & & $n=4$ \\
\hline Locomotion (\%) & $1.5 \pm 0.6$ & $2.3 \pm 1.0^{\#}$ & & $5.7 \pm 1.4^{* *}$ \\
\hline
\end{tabular}

Two-paw and four-paw entries into the open arms of the EPM are highly correlated $(r=0.85 ; p<0.001 ; n=221)$. The number of animals are given for each line and test. Home-cage activity was scored during the regular testing time (8:00 A.M. to 12:00 P.M.), with $n$ indicating the number of cages watched. ${ }^{*} p<0.05,{ }^{* *} p<0.01,{ }^{* * *} p<0.001$ versus corresponding HAB-M; ${ }^{\#} p<0.05,{ }^{\# \#} p<0.01,{ }^{\# \# \#} p<0.001$ versus corresponding LAB-M. 
A

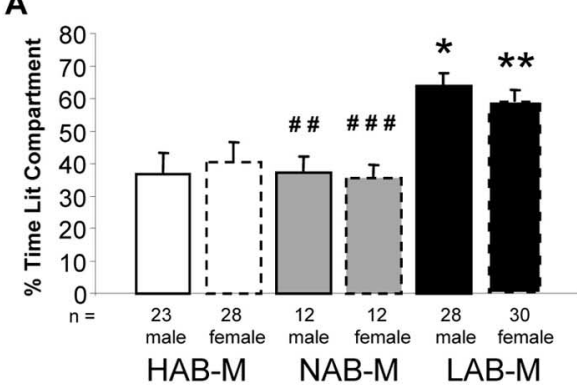

B

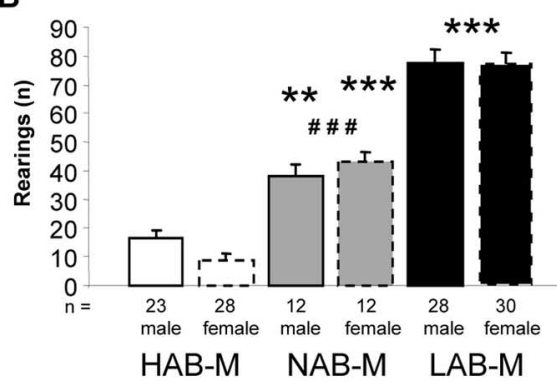

Figure 3. Behavioral data of male and female HAB-M, NAB-M, and LAB-M animals in the dark-light avoidance test. $\boldsymbol{A}, \boldsymbol{B}$, Percentage of time spent in the lit compartment $(\boldsymbol{A})$ and number of rearings $(\boldsymbol{B})$. Number of rearings were measured as total within both the lit and dark compartments. ${ }^{*} p<0.05,{ }^{* *} p<0.01,{ }^{* * *} p<0.001$ versus HAB-M; ${ }^{\# \#} p<0.01$, ${ }^{\# \# \#} p<0.001$ versus LAB-M. Results represent data from G16-G17.

crossings than LAB-M mice $(p<0.01)$ (Table 1$)$. The number of transitions between the dark and the light compartments for HAB-M was lower than that for NAB-M mice (males, $F_{(2,60)}=$ $7.50 ; p<0.01$; females, $\left.F_{(2,67)}=18.1 ; p<0.001\right)$, and the latter made more transitions than LAB-M mice $(p<0.001)$ (Table 1$)$.

\section{Experiment 3: open-arm exposure test}

Male HAB-M mice spent less time with head dipping than LAB-M animals (2.06 vs $\left.9.77 \mathrm{~s} ; F_{(1,18)}=6.52 ; p<0.05\right)$.

\section{Experiment 4: USV test}

HAB-M pups emitted significantly more ultrasound vocalization than LAB-M pups $\left(F_{(2,169)}=18.2 ; p<0.01\right)$ with intermediate levels in NAB-M pups (Table 2). The stress of vehicle administration approximately halved USV calls 30 min after administration, keeping the differences among HAB-M, NAB-M, and LAB-M pups. Diazepam induced a decrease in USV in HAB-M and LAB-M pups and a corresponding tendency in NAB-M pups 30 min after administration. This effect was accompanied by a reduced locomotor activity in LAB-M and NAB-M, but not HAB-M, pups.

\section{Experiment 5: tail-suspension test}

Independent of gender, LAB-M mice displayed significantly less immobility time than HAB-M and NAB-M animals in the tailsuspension test (males, $F_{(2,109)}=105$; females, $F_{(2,82)}=153 ; p<$ 0.001 ) (Fig. 4A). Individual pairs of data (percentage of time EPM vs time spent immobile in the tail-suspension test) revealed a significant correlation $(r=-0.71 ; p<0.001)$ (Fig. 5A).
Experiment 6: forced swim test

Similarly, male and female LAB-M mice displayed significantly less immobility time in the forced swim test than HAB-M, NAB-M, and CM-M mice (males, $F_{(3,138)}=$ 41.3; females, $\left.F_{(3,115)}=61.9 ; p<0.001\right)$ (Fig. $4 B$ ). Individual pairs of data (percentage of time EPM vs time spent immobile in the forced swim test) revealed a significant correlation $(r=-0.54 ; p<0.001)$ (Fig. 5B). Likewise, tail-suspension and forced swim data of HAB-M, NAB-M, and LAB-M mice were highly correlated ( $r=$ $0.66 ; p<0.001$ ) (Fig. 5C).

\section{Experiment 7: proteomic analyses}

For proteomic analyses, protein extracts from individual brain areas were subjected to 2D PAGE. After staining the gels, the scanned images were compared by computer analysis. Each gel contained $\sim 800$ detectable protein spots. One of the protein spots differed significantly in its intensity among all of the HAB-M and LAB-M animals in all three brain areas analyzed (hypothalamus, amygdala, and motor cortex). Based on the signal intensity, the level of expression of this protein was approximately fivefold higher in LAB-M animals compared with HAB-M animals (Fig. 6). The protein was identified by cutting out the stained gel spot and subjecting the protein to in-gel digestion with trypsin followed by tandem mass spectrometry. The obtained tryptic peptide mass spectrometry fragmentation data were used to search the nonredundant protein database and resulted in the identification of the enzyme Glx1. This was the only protein marker found, and there were no other markers in individual brain regions that did not generalize to all regions.

Because 2D PAGE is a rather laborious method for studying protein expression in tissues, we next set up a high-throughput method for the quantitative analysis of Glx1. Because the enzyme is expressed ubiquitously in many cells and tissues (Hayes et al., 1989), we used red blood cells as a source. The protein sequence of Glx1 is highly conserved among higher vertebrates, which allowed us to use a polyclonal antiserum that was generated against human Glx1 for the detection of the mouse enzyme. For this purpose, we set up a Western blot analysis procedure with protein lysates from mouse red blood cells.

The Western blot analysis enabled us to screen a large number of specimens. To extend our studies, we now also included sam-

Table 2. USV of untreated HAB-M, NAB-M, and LAB-M pups and USV and locomotion of HAB-M, NAB-M, and LAB-M pups $30 \mathrm{~min}$ and $24 \mathrm{hr}$ after vehicle or diazepam (2 mg/kg body weight) injection ( $2.5 \mathrm{ml} / \mathrm{kg}$ body weight, i.p.)

\begin{tabular}{|c|c|c|c|c|c|c|}
\hline & \multicolumn{2}{|l|}{ HAB-M } & \multicolumn{2}{|l|}{ NAB-M } & \multicolumn{2}{|l|}{ LAB-M } \\
\hline \multicolumn{7}{|l|}{ USV } \\
\hline \multirow[t]{3}{*}{ Untreated } & \multicolumn{2}{|l|}{$220 \pm 15.7(65)^{\# \#}$} & \multicolumn{2}{|l|}{$154 \pm 15.3(67)^{* * \text {,\#\# }}$} & \multicolumn{2}{|l|}{$94.5 \pm 15.7(54)^{* *}$} \\
\hline & \multicolumn{2}{|l|}{ HAB-M } & \multicolumn{2}{|l|}{ NAB-M } & \multicolumn{2}{|l|}{ LAB-M } \\
\hline & 30 min after injection & $24 \mathrm{~h}$ after injection & 30 min after injection & $24 \mathrm{~h}$ after injection & 30 min after injection & $24 \mathrm{~h}$ after injection \\
\hline \multicolumn{7}{|l|}{ USV } \\
\hline Vehicle & $119 \pm 21.8^{\# \#(8)}$ & $200 \pm 33.3^{\# \#}(9)$ & $88.9 \pm 10.5^{\#}(9)$ & $125 \pm 5.6^{* \# \#}(10)$ & $40.1 \pm 11.4^{* *}(10)$ & $43.1 \pm 10.7^{* *}(10)$ \\
\hline Diazepam & $30.1 \pm 8.2^{++, \#}(8)$ & $110 \pm 23.3^{\# \#}(9)$ & $44.8 \pm 7.9^{\# \#}(10)$ & $93.8 \pm 11.7^{\# \#}(10)$ & $5.1 \pm 3.0^{++, *}(10)$ & $13.2 \pm 7.6^{* *}(10)$ \\
\hline \multicolumn{7}{|l|}{ Locomotion } \\
\hline Vehicle & $17.5 \pm 2.9(8)$ & $19.6 \pm 3.9(9)$ & $41.4 \pm 8.6(10)$ & $39.9 \pm 4.4^{\# \#(10)}$ & $21.4 \pm 4.0(10)$ & $11.2 \pm 1.5(10)$ \\
\hline Diazepam & $15.5 \pm 4.4^{\# \#}(8)$ & $21.2 \pm 4.6(9)$ & $17.8 \pm 3.9^{+}(10)$ & $20.3 \pm 2.6^{++, \# \#}(10)$ & $5.8 \pm 1.1^{++, * *}(10)$ & $4.2 \pm 1.1(10)$ \\
\hline
\end{tabular}

The number of pups is given in parentheses; pups/group are from at least three litters. ${ }^{*} p<0.05$, ${ }^{* *} p<0.01$ versus corresponding HAB-M; ${ }^{\#} p<0.05,{ }^{\# \#} p<0.01$ versus corresponding LAB-M; ${ }^{+} p<0.05,{ }^{++} p<0.01$ versus corresponding vehicle. 
ples from NAB-M and CM-M controls. Independent of their gender, both groups, NAB-M and CM-M animals, showed intermediate levels of Glx1 expression compared with LAB-M and HAB-M mice, the former again expressing significantly more Glx1 (male, $F_{(3,31)}=45.9$; female, $F_{(2,22)}=$ 84.5; $p<0.001$ ) (Fig. 7), thus confirming the brain tissue data (Fig. 6).

An additional validation of Glx1 as a biomarker of trait anxiety in mice was achieved by the following two experiments. First, similar to LAB-M versus HAB-M animals, BALB/c mice expressed more Glxl than the more anxious C57BL/6 animals $(p<0.01)$ (Fig. 8). Second, based on Glx1 expression in 17 blood samples, the HAB-M versus LAB-M phenotypes could unambiguously be identified in a blind manner (Fig. 9).

\section{Experiment 8: microarray}

The microarray analysis revealed an upregulation of the Glx1 gene (Glo1) in the hypothalamic PVN of LAB-M animals (2.16to 2.44-fold; $p<0.01$ ) compared with HAB-M animals. This is shown by three independent spots on the arrays containing different cDNAs (GenBank accession numbers AI851782, AI852001, and AI848952) (Fig. 10).

\section{Discussion}

Similar to HAB/LAB Wistar rats (Landgraf and Wigger, 2002, 2003; Landgraf and Neumann, 2004; Murgatroyd et al., 2004; Wigger et al., 2004), selective and bidirectional breeding of CD1 mice for either high- or low-anxiety-related behavior resulted in two inbred lines that, independent of their gender, differ extremely in a variety of behavioral paradigms. The EPM, based on spontaneous, unconditioned behavior, was selected as an initial key evaluation tool. The degree of avoidance of the open arms on the maze that is considered a measure of the genetic predisposition for trait anxiety is also predictive for stress coping (Ducottet and Belzung, 2004) and behavior in other anxiety tests (Trullas and Skolnick, 1993; Henderson et al., 2004). Indeed, HAB-M mice were not only more anxious compared with LAB-M mice in the EPM and dark-light tests but also showed fewer signs of risk assessment and emitted more USV calls, all measures that are indicative of a high-anxiety level. Furthermore, in both the forced swim and tail-suspension tests, LAB-M animals showed lower scores of immobility than HAB-M and NAB-M animals, indicative of a reduced depression-like behavior. Using combined proteomic (hypothalamus, amygdala, cortex, and red blood cells) and microarray (hypothalamic PVN) approaches, Glx1 was identified as a protein marker, which is consistently expressed to a higher extent in LAB-M than in HAB-M mice.

As shown in Figure 1, the divergence between the HAB-M and LAB-M lines steadily increased to reach its maximum after approximately nine generations. The breeding protocol continued by strict sibling mating, resulting in a conservation of genetic polymorphisms underlying either high- or low-trait anxiety. CM-M animals showed intermediate behavior on the EPM, thus mimicking the anxiety-related behavior of NAB-M mice. Similarly, the latter emitted USV calls with an intermediate frequency that is exactly between those produced by HAB-M and LAB-M mice (Table 2). This anxiety index reflecting differences in an infantile trait as a consequence of the selective breeding of adults

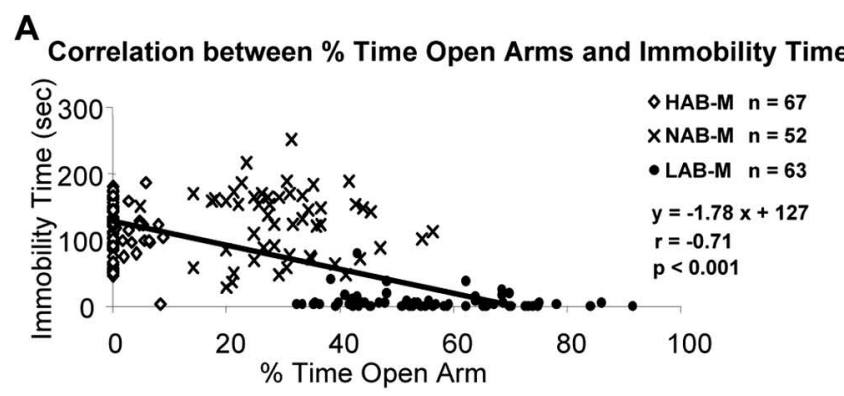

B Correlation between \% Time Open Arms and Floating Time

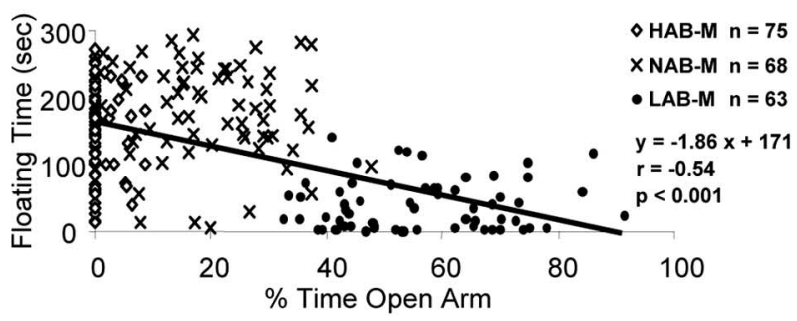

C

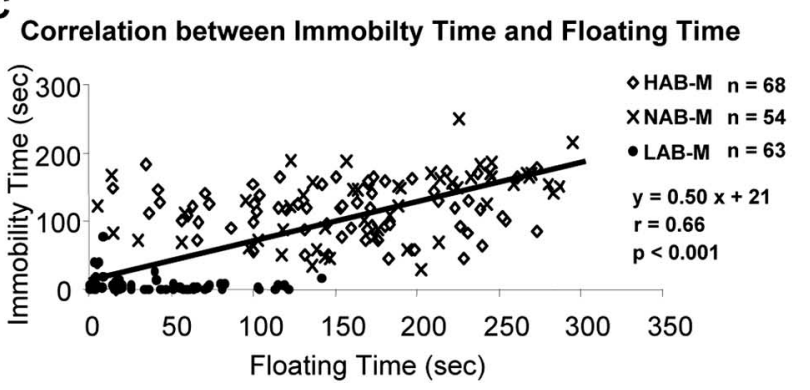

Figure 5. $\quad \boldsymbol{A}-\boldsymbol{C}$, Correlation analyses of anxiety- and depression-like indices ( $\boldsymbol{A}$, percentage of time open-arms EPM vs immobility time in the tail-suspension test; $\boldsymbol{B}$, percentage of time open-arms EPM vs floating time in the forced swim test) and between depression-like indices ( $\boldsymbol{C}$, immobility time in the tail-suspension test vs floating time in the forced swim test). Data from male and female animals of $\mathrm{G} 14-\mathrm{G} 15$ are shown.

(Brunelli et al., 1997) was measured at P5, further supporting a genetic predisposition. Importantly, young developing animals may be more sensitive to drug treatments than adults, thus mitigating the problem of considerable interstrain differences in drug sensitivity (Cryan and Mombereau, 2004; Fish et al., 2004). The differences in maternal separation-induced USV persisted even after vehicle administration. Diazepam reduced USV emission to a similar extent in all three lines (Table 2). This result confirms previous studies measuring USV in rodent pups after 
treatment with clinically effective drugs (Benton and Nastiti, 1988). In contrast to NAB-M and LAB-M pups, however, locomotor activity of HAB-M animals was not influenced by diazepam. Although, in CD1 pups, USV emission was shown to be associated with locomotor activity (Branchi et al., 2004), it is probably too premature to suggest a predominantly anxiolytic effect of diazepam in HAB-M pups. In adult mice, diazepam reduced anxiety (dark-light and EPM tests) and induced dosedependent effects on locomotor activity (Crawley and Davis, 1982; Griebel et al., 2000).

Additional profiling of anxiety-related behavior was achieved by performing detailed videotaped analyses of mice in different tests, yielding a catalog of readily identifiable behaviors that have been referred to as risk assessment, including head dipping and rearing, a particularly important anxiety measure (Henderson et al., 2004). Although risk assessment behavior confirmed the marked difference in trait anxiety between HAB-M and LAB-M animals, the forced swim and tail-suspension tests rather reflect depression-like behavior (Cryan et al., 2002; Yoshikawa et al., 2002; Cryan and Mombereau, 2004). The significant correlation between anxietyand depression-related behaviors resembles the clinical situation of a high comorbidity between anxiety disorders and depression (Levine et al., 2001). The correlation in mice, however, is primarily attributable to the extremely lowdepression-like behavior of LAB-M mice, whereas HAB-M mice did not significantly differ from NAB-M and CM-M controls, respectively. This is true for both the forced swim and tail-suspension tests (Fig. 4), despite the fact that the neural circuitry mediating behavior in these tests is not identical (Bai et al., 2001). Thus, although HAB-M and LAB-M mice selectively bred for a specific anxiety-related phenotype (EPM) show similar differences across a variety of anxiety- and depression-related behavioral paradigms, HAB-M animals show little difference from NAB-M or CM-M controls in depression-related tests. These findings suggest that testdependent facets of behavior are involved with at least partially different genetic mechanisms controlling the various anxiety- and depression-related indices. Additional studies will focus on the phenomenon of intermediate behavior of NAB-M and CM-M animals in anxietyrather than depression-related tests. It is noteworthy that, in this context, the former reflects the primary selection criterion, whereas no selection pressure was exerted on depression-related indices.

A variety of parameters reflecting locomotor activity are listed in Table 1 . The data essentially confirm other reports demonstrating lower activity of mice showing high levels of anxiety- and depression-like behavior (Suaudeau et al., 2000; Do-Rego et al., 2002; El Yacoubi et al., 2003) and vice versa (Ferguson et al., 2004). However, some of the indices presented in Table 1 are contaminated (i.e., reflect
A

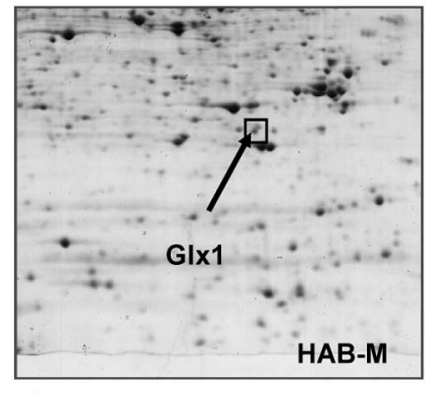

B

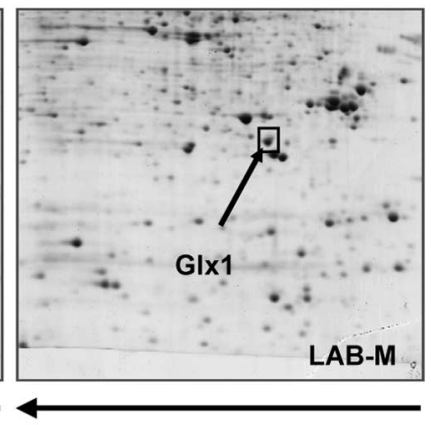

7

47

4

Figure 6. Representative 2D PAGE of amygdala protein extracts from a male HAB-M animal $(\boldsymbol{A})$ and a male LAB-M animal $(\boldsymbol{B})$. The difference in the expression of $\mathrm{Gl} 1 \mathrm{x}$ is indicated by the arrow. The pH gradient of the first-dimension isoelectric focusing is indicated at the bottom of the gels. Results represent data from G12; a total of eight animals were analyzed for each group.
A

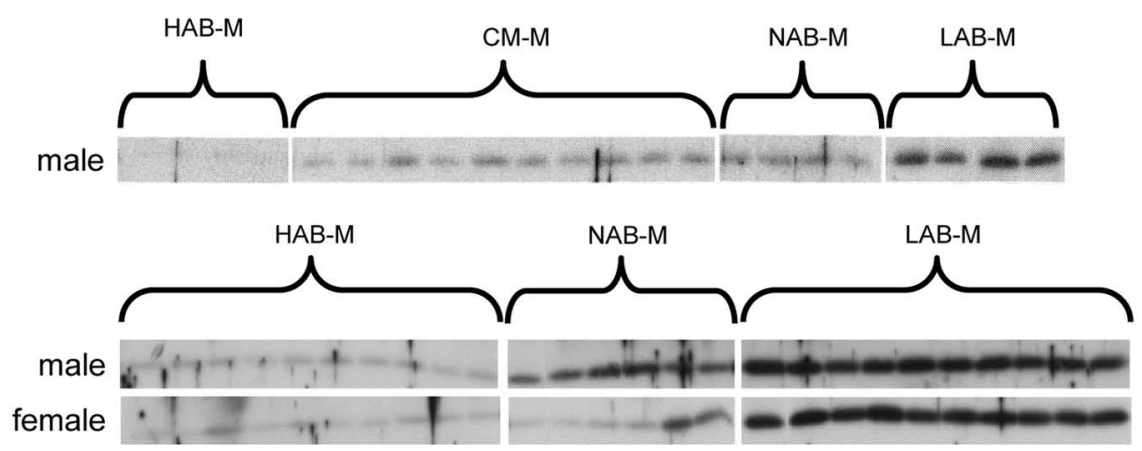

B

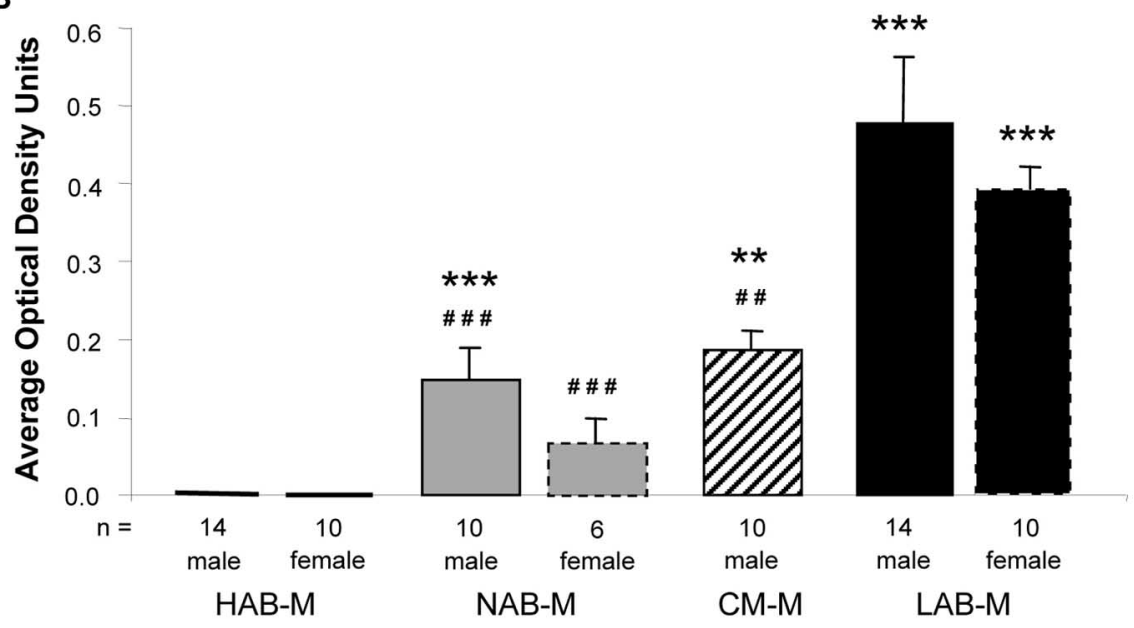

Figure 7. Western blot analysis of red blood cell protein extracts from male HAB-M, NAB-M, CM-M, and LAB-M animals. Red cell extracts representing equal amounts of total protein $(100 \mu \mathrm{g})$ were run on a 12\% SDS gel and transferred to a PVDF membrane. Subsequently, the membrane was probed with an anti-Glx1-specific antibody and developed. The immunoreactive $G \mid x 1$ protein bands are shown $(\boldsymbol{A})$. The signal volumes of the bands obtained from Western blot analysis in $A$ were quantified with a densitometer, and means + SEM of optical density for each animal group are shown $(\boldsymbol{B}) .{ }^{* *} p<0.01$, ${ }^{* * *} p<0.001$ versus HAB-M; ${ }^{\# \# \#}<0.001$ versus LAB-M. Results represent data from G14-G17. both locomotor activity and anxiety, e.g., ratio open/total entries EPM) (File, 2001), and attempts to distinguish between activitybased and anxiety-based behavioral phenotypes in a test apparatus can be misleading (Henderson et al., 2004). Therefore, we 


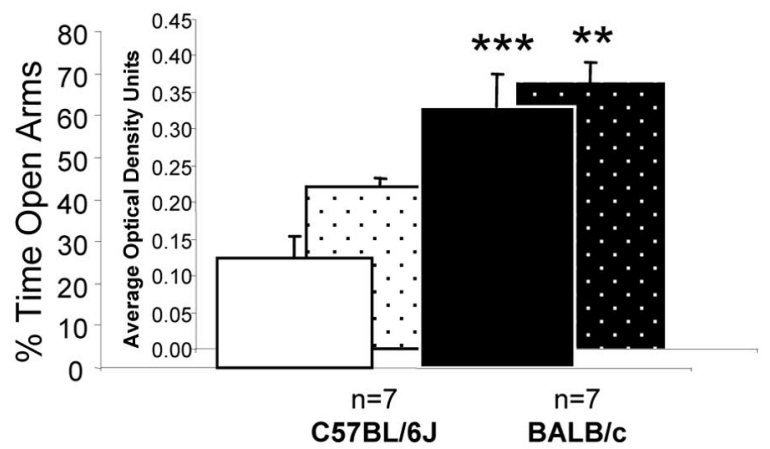

Figure 8. Validation of $\mathrm{Gl} 1 \mathrm{1}$ as a biomarker of trait anxiety in inbred mouse strains differing in their EPM behavior (percentage of time open arms). Male BALB/c mice expressed more GIx1 than the more anxious male $(57 \mathrm{BL} / 6$ mice $(C 57 \mathrm{BL} / 6)$ ), thus supporting the data presented in Figure $7 .{ }^{* *} p<0.05,{ }^{* * *} p<0.01$ versus $\mathrm{C} 57 \mathrm{BL} / 6$.

additionally tested home-cage activity, which confirmed that male and female LAB-M mice show higher levels of activity than HAB-M and NAB-M animals (Table 1). Although, dependent on the behavioral test used (Suaudeau et al., 2000), this difference in locomotor activity may potentially contribute to the selection phenotypes (Figs. 3A, 4), it certainly does not explain differences in anxiety-related behavior between HAB-M and NAB-M animals, as shown in Figures 2 and $3 B$. It is noteworthy that, in this context, the suppression of locomotor activity is one of cross-test dimensions of anxiety (Henderson et al., 2004).

We attempted to reduce the risk of genetic drift across time to cause divergences in the selection phenotype as described, for example, by El Yacoubi et al. (2003) for locomotor activity and confounds to the interpretation of correlated responses to selection in the following manner. First, we generated parallel and independent families within the HAB-M and LAB-M lines, and members of all families were used in the experiments. Second, we included both NAB-M and CM-M controls. Third, we tested correlated responses over many generations. To further improve the strength of our data, we attempted to meet the criteria that, according to Geyer and Markou (1995), are necessary and sufficient for the initial use of an animal model, namely predictive validity and reliable and robust behavioral readouts in the same laboratory and between different laboratories. In our study, the key behavioral measures reflecting predictive validity have been repeatedly confirmed across the generations (e.g., percentage of time spent on the open arms of the EPM) (Fig. 1) and under varying experimental conditions (e.g., USV calls) (Table 2). The issue of reproducibility and reliability of behavioral data across laboratories is an important consideration in all aspects of behavioral analyses (Crabbe et al., 1999; Wahlsten et al., 2003). Although no attempts were made to standardize test procedures, the behavioral measures presented here were highly consistent across our laboratory at

GIX1

Line the Max-Planck Institute of Psychiatry, the University of Regensburg (EPM) (I. D. Neumann, personal communication) and the University of Innsbruck (EPM, open-arm exposure) (N. Singewald, personal communication).

A major goal in the area of mental disorders is the identification of biomarkers that can categorize subsets of subjects in a more reliable and consistent manner. Our approach demonstrates that proteomic analyses are suited to identify a protein marker that is differentially expressed in CD1 mice with different genetic predispositions to anxiety, namely Glx1. Glx1 represents an enzyme in the cytosolic fraction of cells and tissues of many organisms. Although its function is not entirely clear, it has been shown that the enzyme plays a major role in the detoxification of methylglyoxal, which represents a potent cytotoxic metabolite. Glx1 catalyzes the transformation of methylglyoxal and glutathione to $S$-lactoylglutathione, which is converted to D-lactic acid by glyoxalase-II (Thornalley, 1993). Because of its ubiquitous expression, the glyoxal pathway is believed to be of fundamental importance for cellular metabolism.

Recently, Glx1 was identified as the only upregulated gene in mutant mice sharing common pathogenic mechanisms with Alzheimer's disease patients (Chen et al., 2004). A possible connection between Glx1 and depression has been found in a linkage study of families with depressive disease. Subgroups of families with unipolar affective disease showed evidence for a linkage or association with the Glx1 locus; unfortunately, the level of anxiety was not described in this study (Tanna et al., 1989).
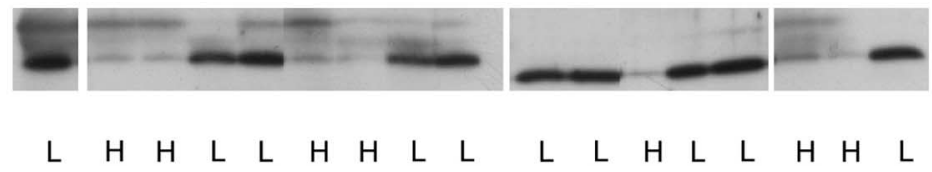

Figure 9. Predictive validity of Glx1 as a biomarker of trait anxiety. Based on Glx1 expression in (unknown) blood samples, the HAB-M (H) versus LAB-M (L) phenotypes could unambiguously be identified in a blind manner. The results of 17 samples from Western blot analysis using an anti-Glx1-specific antibody are shown. Results represent data from G16-G17.

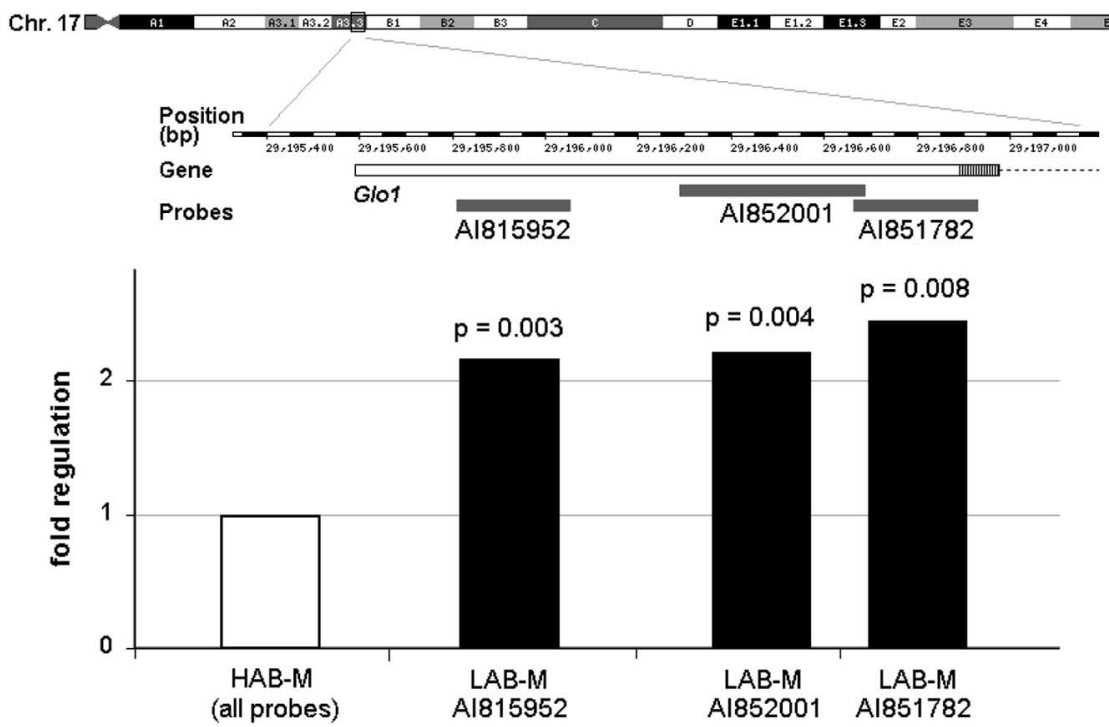

Figure 10. Microarray analysis of Glx1 gene (Glo1) expression. Chromosomal origin of the Glx1 gene, location of the CDNA probes used in the microarrays, and GIx 1 mRNA expression in the hypothalamic PVN of male LAB-M and HAB-M mice; $n=3$ each; PVNs from 2 animals were pooled into one sample) are shown. As the fold regulation values are backtransformed from a logarithmic scale, the value for HAB-M is 1.0; all other values represent the fold gene regulation in LAB-M compared with HAB-M. The design is based on Ensembl (www.ensembl.org); data are from the National Center for Biotechnology Information (www.ncbi.nIm.nih.gov). Results represent data from G18. 
In our newly developed mouse model of extremes in trait anxiety, Glx1 in brain areas and blood cells has been shown to represent a robust, reliable biomarker for the nonanxious versus anxious phenotype. While expressed at an intermediate level in unselected NAB-M as well as CM-M controls, it showed a bidirectional shift from the strain mean toward reduced (HAB-M; but no significant difference between NAB-M and HAB-M females) and increased (LAB-M) expression levels (Fig. 7), thus mimicking the anxiety phenotype (Fig. $2 A$ ). The validity of Glx1 as a protein marker of trait anxiety is further confirmed by the following approaches. First, the microarray analysis revealed that the Glxl gene exhibits differential expression in the hypothalamic PVN with LAB-M expressing more than twice as much mRNA than HAB-M animals (Fig. 10), thus confirming our proteomic results (Fig. 6). Second, to elaborate on the use of CD1 as the strain of choice, we additionally tested Glx1 in inbred strains that are more or less anxious. Indeed, confirming their EPM behavior described previously (Trullas and Skolnick, 1993; Griebel et al., 2000; Ducottet and Belzung, 2004), BALB/c mice expressed more protein marker than the more anxious C57BL/6 animals (Fig. 8), thus mimicking our LAB-M versus HAB-M data (Fig. 7). Third, based on Glx1 expression, we were able to unambiguously identify the HAB-M and LAB-M phenotypes in 17 blood samples in a blind manner (Fig. 9).

The predictive validity of Glx1 to identify different levels of trait anxiety provides the basis for future testing, including its impact beyond that of a biomarker, i.e., does it contribute to rather than merely parallel the manifestation of trait anxiety? To answer this question and to further pursue the functional implications of Glx1, behavioral and protein studies across an F2 panel and a larger number of inbred strains will be performed in our laboratory. Thus, similar to its role in Alzheimer's disease (Chen et al., 2004), a broad range of functional approaches will be used to study the possible involvement of Glx1 in anxiety-related behavior, including psychopathology.

\section{References}

Bai F, Li X, Clay M, Lindstrom T, Skolnick P (2001) Intra- and interstrain differences in models of "behavioral despair." Pharmacol Biochem Behav 70:187-192.

Benton D, Nastiti K (1988) The influence of psychotropic drugs on the ultrasonic calling of mouse pups. Psychopharmacology (Berl) 95:99-102.

Branchi I, Santucci D, Puopolo M, Alleva E (2004) Neonatal behaviors associated with ultrasonic vocalizations in mice (mus musculus): a slowmotion analysis. Dev Psychobiol 44:37-44.

Brunelli SA, Vinocur DD, Soo-Hoo D, Hofer MA (1997) Five generations of selective breeding for ultrasonic vocalization (USV) responses in N:NIH strain rats. Dev Psychobiol 31:255-265.

Brush FR (2003) The Syracuse strains, selectively bred for differences in active avoidance learning, may be models of genetic differences in trait and state anxiety. Stress 6:77-85.

Chen F, Wollmer MA, Hoerndli F, Munch G, Kuhla B, Rogaev EI, Tsolaki M, Papassotiropoulos A, Gotz J (2004) Role for glyoxalase I in Alzheimer's disease. Proc Natl Acad Sci USA 101:7687-7692.

Crabbe JC, Wahlsten D, Dudek BC (1999) Genetics of mouse behavior: interactions with laboratory environment. Science 284:1670-1672.

Crawley JN, Davis LG (1982) Baseline exploratory activity predicts anxiolytic responsiveness to diazepam in five mouse strains. Brain Res Bull 8:609-612.

Cryan JF, Mombereau C (2004) In search of a depressed mouse: utility of models for studying depression-related behavior in genetically modified mice. Mol Psychiatry 9:326-357.

Cryan JF, Markou A, Lucki I (2002) Assessing antidepressant activity in rodents: recent developments and future needs. Trends Pharmacol Sci 23:238-245.

Do-Rego J-C, Suaudeau C, Chapouthier G, Costentin J (2002) Mouse lines differing in sensitivity to $\beta$-CCM differ in tasks used for testing antidepressants. Pharmacol Biochem Behav 72:411-416.

Ducottet C, Belzung C (2004) Behaviour in the elevated plus-maze predicts coping after subchronic mild stress in mice. Physiol Behav 81:417-426.

El Yacoubi M, Bouali S, Popa D, Naudon L, Leroux-Nicollet I, Hamon M, Costentin J, Adrien J, Vaugeois J-M (2003) Behavioral, neurochemical, and electrophysiological characterization of a genetic mouse model of depression. Proc Natl Acad Sci USA 100:6227-6232.

Falconer DS, Mackay TFC (1996) Introduction to quantitative genetics. Essex, UK: Pearson.

Ferguson GD, Herschman HR, Storm DR (2004) Reduced anxiety and depression-like behavior in synaptotagmin IV $(-/-)$ mice. Neuropharmacology 47:604-611.

File SE (2001) Factors controlling measures of anxiety and responses to novelty in the mouse. Behav Brain Res 125:151-157.

Finn DA, Rutledge-Gorman MT, Crabbe JC (2003) Genetic animal models of anxiety. Neurogenetics 4:109-135.

Fish EW, Faccidomo S, Gupta S, Miczek KA (2004) Anxiolytic-like effects of escitalopram, citalopram, and $R$-citalopram in maternally separated mouse pups. J Pharmacol Exp Ther 308:474-480.

Geyer MA, Markou A (1995) Animal models of psychiatric disorders. In: Psychopharmacology: the fourth generation of progress (Bloom FE, Kupfer DJ, eds), pp 787-798. New York: Raven.

Gordon JA, Hen R (2004) Genetic approaches to the study of anxiety. Annu Rev Neurosci 27:193-222.

Griebel G, Belzung C, Perrault G, Sanger DJ (2000) Differences in anxietyrelated behaviours and in sensitivity to diazepam in inbred and outbred strains of mice. Psychopharmacology 148:164-170.

Gross C, Hen R (2004) The developmental origins of anxiety. Nat Rev Neurosci 5:545-552.

Hayes JD, Milner SW, Walker SW (1989) Expression of glyoxalase, glutathione peroxidase and glutathione $S$-transferase isoenzymes in different bovine tissues. Biochim Biophys Acta 994:21-29.

Henderson ND, Turri MG, DeFries JC, Flint J (2004) QTL analysis of multiple behavioral measures of anxiety in mice. Behav Genet 34:267-293.

Henniger MS, Ohl F, Holter SM, Weissenbacher P, Toschi N, Lorscher P, Wigger A, Spanagel R, Landgraf R (2000) Unconditioned anxiety and social behaviour in two rat lines selectively bred for high and low anxietyrelated behaviour. Behav Brain Res 111:153-163.

Kalisch R, Salomé N, Platzer S, Wigger A, Czisch M, Sommer W, Singewald N, Heilig M, Berthele A, Holsboer F, Landgraf R, Auer DP (2004) High trait anxiety and hyporeactivity to stress of the dorsomedial prefrontal cortex: a combined phMRI and Fos study in rats. NeuroImage 23:382-391.

Keck ME, Wigger A, Welt T, Muller MB, Gesing A, Reul JM, Holsboer F, Landgraf R, Neumann ID (2002) Vasopressin mediates the response of the combined dexamethasone/CRH test in hyper-anxious rats: implications for pathogenesis of affective disorders. Neuropsychopharmacology 26:94-105.

Landgraf R, Neumann ID (2004) Vasopressin and oxytocin release within the brain: a dynamic concept of multiple and variable modes of neuropeptide communication. Front Neuroendocrinol 25:150-176.

Landgraf R, Wigger A (2002) High vs low anxiety-related behavior rats: an animal model of extremes in trait anxiety. Behav Genet 32:301-314.

Landgraf R, Wigger A (2003) Born to be anxious: neuroendocrine and genetic correlates of trait anxiety in HAB rats. Stress 6:111-119.

Levine J, Cole DP, Chengappa KN, Gershon S (2001) Anxiety disorders and major depression, together or apart. Depress Anxiety 14:94-104.

Murgatroyd C, Wigger A, Frank E, Singewald N, Bunck M, Holsboer F, Landgraf R, Spengler D (2004) Impaired repression at a vasopressin promoter polymorphism underlies overexpression of vasopressin in a rat model of trait anxiety. J Neurosci 24:7762-7770.

Ohl F, Toschi N, Wigger A, Henniger MS, Landgraf R (2001) Dimensions of emotionality in a rat model of innate anxiety. Behav Neurosci 115:429-436.

Ohta R, Shirota M, Adachi T, Tohei A, Taya K (1999) Plasma ACTH levels during early, two-way avoidance acquisition in high- and low-avoidance rats (Hatano strains). Behav Genet 29:137-144.

Overstreet DH, Commissaris RC, De La GR, File SE, Knapp DJ, Seiden LS (2003) Involvement of 5- $\mathrm{HT}_{1 \mathrm{~A}}$ receptors in animal tests of anxiety and depression: evidence from genetic models. Stress 6:101-110.

Paxinos G, Franklin K (2001) The mouse brain in stereotaxic coordinates. San Diego: Academic. 
Salomé N, Salchner P, Viltart O, Sequeira H, Wigger A, Landgraf R, Singewald N (2004) Neurobiological correlates of high (HAB) versus low anxietyrelated behavior (LAB): differential Fos expression in HAB and LAB rats. Biol Psychiatry 55:715-723.

Steimer T, Driscoll P (2003) Divergent stress responses and coping styles in psychogenetically selected Roman high-(RHA) and low-(RLA) avoidance rats: behavioural, neuroendocrine and developmental aspects. Stress 6:87-100.

Suaudeau C, Rinaldi D, Lepicard E, Venault P, Crusio WE, Costentin J, Chapouthier G (2000) Divergent levels of anxiety in mice selected for differences in sensitivity to a convulsant agent. Physiol Behav [Erratum (2001) 72:453] 71:517-523.

Tanna VL, Wilson AF, Winokur G, Elston RC (1989) Linkage analysis of pure depressive disease. J Psychiatry Res 23:99-107.

Tarantino LM, Bucan M (2000) Dissection of behavior and psychiatric disorders using the mouse as a model. Hum Mol Genet 9:953-965.

Thornalley PJ (1993) The glyoxalase system in health and disease. Mol Aspects Med 14:287-371.

Trullas R, Skolnick P (1993) Differences in fear motivated behaviors among inbred mouse strains. Psychopharmacology (Berl) 111:323-331.

Wahlsten D, Metten P, Phillips TJ, Boehm SL, Burkhart-Kasch S, Dorow J,
Doerksen S, Downing C, Fogarty J, Rodd-Henricks K, Hen R, McKinnon CS, Merrill CM, Nolte C, Schalomon M, Schlumbohm JP, Sibert JR, Wenger CD, Dudek BC, Crabbe JC (2003) Different data from different labs: lessons from studies of gene-environment interaction. J Neurobiol 54:283-311.

Wigger A, Loerscher P, Weissenbacher P, Holsboer F, Landgraf R (2001) Cross-fostering and cross-breeding of $\mathrm{HAB}$ and $\mathrm{LAB}$ rats: a genetic rat model of anxiety. Behav Genet 31:371-382.

Wigger A, Sánchez MM, Mathys KC, Ebner K, Liu D, Kresse A, Neumann ID, Holsboer F, Plotsky PM, Landgraf R (2004) Alterations in central neuropeptide expression, release, and receptor binding in rats bred for high anxiety: critical role of vasopressin. Neuropsychopharmacology 29:1-14.

Yang YH, Dudoit S, Luu P, Lin DM, Peng V, Ngai J, Speed TP (2002) Normalization for cDNA microarray data: a robust composite method addressing single and multiple slide systematic variation. Nucleic Acids Res 30:e15.

Yoshikawa T, Watanabe A, Ishitsuka Y, Nakaya A, Nakatani N (2002) Identification of multiple genetic loci linked to the propensity for "behavioral despair" in mice. Genome Res 12:357-366. 